\title{
Managing the Impact of a Mutating Global Crisis on Organizations
}

\author{
Deepraj Mukherjee ${ }^{1}$ (D) Debmalya Mukherjee ${ }^{2}$
}

Accepted: 18 February 2021 / Published online: 20 April 2021

(C) International Atlantic Economic Society 2021

JEL $\quad \mathrm{H} 12 \cdot \mathrm{L} 1 \cdot \mathrm{L} 2 \cdot \mathrm{F} 2$

A mutating global crisis event, such as the ongoing pandemic, initially results in local or regional uncertainties but rapidly affects the global economy. While organizations often have contingency plans for unexpected disruptions, the continuously mutating nature of the COVID-19 crisis has severed global connectivity, disrupted business functions, and changed the nature of the relationship of businesses with employees and customers. How should organizational leaders tackle such fluid and constant crises that may have a long-term impact at so many levels? To answer this question, this article offers a new evidence-based, 4A framework (anticipate, analyze, adapt, and act). The novelty of this approach is that it combines different streams of literature under an overarching framework aimed at helping strategic leaders.

Though mutating global crises start suddenly, managers may anticipate such events by continuously scanning their environment and making sense of the signals (Thomas et al., Academy of Management Journal, 1993) based on some common defining characteristics (Williams et al., Academy of Management Annals, 2017). Research in crisis management (James et al., Academy of Management Annals, 2017) shows that such events quickly become prevalent by increasing their global scope and have a severe negative impact on different levels of society (e.g., companies, government, regulating agencies, financial intermediaries). Additionally, the rate of spread of negative financial contagion (Allen and Gale, Journal of Political Economy, 2000), or how quickly the crisis spreads to different parts of the globe and

Deepraj Mukherjee

dmukherj@kent.edu

1 Department of Economics, College of Business Administration, Kent State University, Kent, $\mathrm{OH} 44240$, USA

2 Department of Management, College of Business Administration, University of Akron, Akron, OH 44325, USA 
detrimentally affects the financial health of value-creating entities, is another defining characteristic of such events.

Next, managers need to analyze how a mutating crisis may stimulate their organization to formulate responses and manage the evolving situation. The ongoing pandemic shows that such events have three main types of disruptive effects on organizations: structural, functional, and relational. In a time of global interdependencies, today's organizations are heavily dependent on global linkages (Pittiglio and Reganati, Atlantic Economic Journal, 2015).

For instance, from a structural vantage point, firms rely on the supply of critical inputs such as raw materials, parts, components, global talents, and services. Yet, during crisis events, such linkages are disrupted and even restricted (Ivanov and Dolgui, International Journal of Production Economics, 2021). Structural disruptions and changes in the external environment alter the internal business functions of an organization. Indeed, many organizations worldwide shut down their manufacturing plants and furloughed or laid off large numbers of employees due to the COVID-19 crisis. However, such a crisis may also have the opposite effect, acting as a positive disruption for some companies. For instance, producers of cleaning supplies and hand sanitizers are now experiencing a huge surge in sales during the ongoing pandemic, compelling such companies to hire extra workers and stretch existing resources to meet the upward demand.

Moreover, such spiraling crisis events also change the relational contract between organizations and their employees. Crisis evokes low morale and heightened levels of uncertainty among employees. They may be asked to work overtime, change their normal working hours, and be given different roles. These changes may result in frustration, role ambiguity, stress, and low job satisfaction, factors that can lead to pent up turnovers when the situation normalizes.

While adapting to structural disruptions of a global nature, managers may need to look for local or regional solutions. For example, research on industrial clusters demonstrates that although increasingly more companies depend on globally distributed innovation systems, those rooted within the local community, such as educational institutions, research labs, and start-ups, are more resilient during crisis events and have a higher probability of survival in the post-crisis period (Mudambi et al., Industrial Marketing Management, 2017).

Crisis events tend to isolate the different functional entities of an organization. To manage functional disruptions, managers should ensure that the organization's external knowledge ties are not severed. Furthermore, they need to identify which resources are most important to maintain core organizational functions and which resources can be reallocated to mitigate unexpected internal changes. It is also important to keep coordinating mechanisms integrated within the organization for a unified response to the crisis.

Employees and customers represent the two most proximal stakeholders for organizations. Research indicates that a positive attitude is considered an intangible resource used to manage relational disruption in moments of crisis. Thus, prioritizing employee and customer wellbeing and effectively reassuring employees and customers through various communication channels is vital when a crisis hits. This people-first approach may also have long-term benefits for the focal organization 
in terms of an increased sense of belonging, organizational identification, and customer loyalty.

Finally, scientific evidence points toward common factors that underlie effective managerial actions during crisis events: timeliness and decisiveness. Studies related to disaster response show that acting swiftly reassures affected people and may stop the crisis event from having a spiraling negative effect on the organization (Boettke et al., Southern Economic Journal, 2007). Moreover, being decisive during crisis events may signal confidence and can define how an organization is viewed by its main stakeholders.

In sum, organizations that are nimble and prepared can tackle unforeseen emergencies. The ability to convert a crisis into an opportunity is the key to organizational success and long-term competitive advantage. We posit that while it is not possible to provide a blanket prescription to deal with a global mutating crisis of this magnitude, the current endeavor should provide effective guidelines for future research in related areas.

Publisher's Note Springer Nature remains neutral with regard to jurisdictional claims in published maps and institutional affiliations. 